\title{
National Consensus Statement on the Management of Type 2 Diabetes Mellitus in Nepal
}

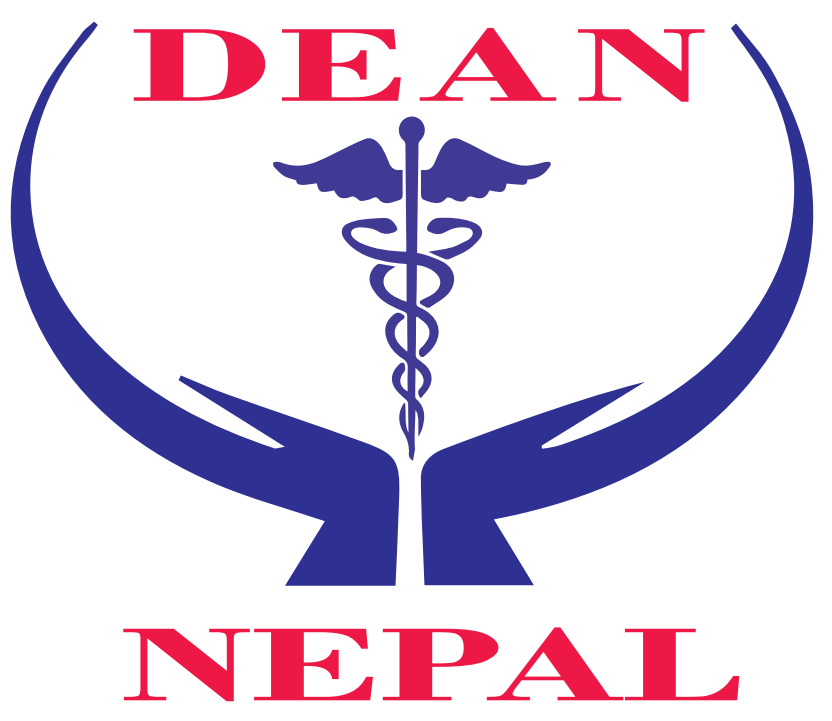

Chief Editor

Dr Dina Shrestha

Core Committee Members

Prof Pradeep Shrestha

Prof Sanjib Sharma

Dr Jyoti Bhattarai

Dr Hari Kumar Shrestha

Dr Ajay Pradhan

Dr Amit Shakya 


\section{Contents}

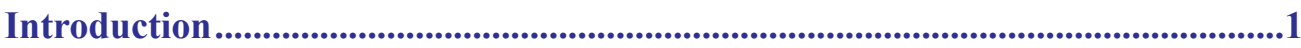

Screening for T2DM ...............................................................................................................1

Diagnostic Criteria for T2DM .................................................................................

Assessment of Glycaemic Control ................................................................................2

Monitoring and Follow-up ..........................................................................................2

Management of T2DM ....................................................................................................2

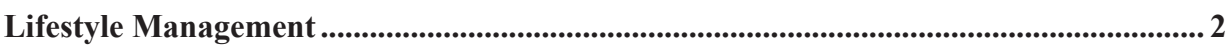

Pharmacological Management ........................................................................................................... 3

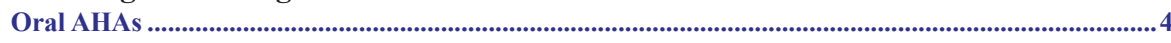

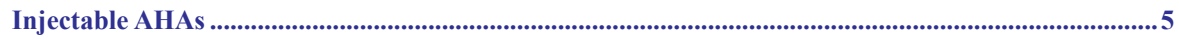

Management of Complications of T2DM ....................................................................6

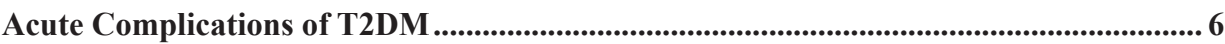

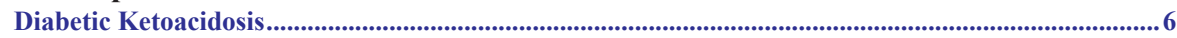

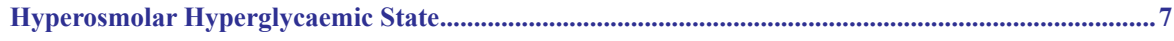

Hypoglycaemia …...................................................................................................................................................

Microvascular Complications of T2DM ................................................................................... 7

Diabetes Kidney Disease..............................................................................................................................

Diabetic Retinopathy ............................................................................................................................

Diabetic Neuropathy ............................................................................................................................................9

Macrovascular Complications of T2DM ................................................................................ 9

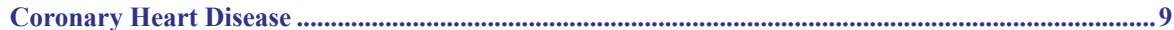

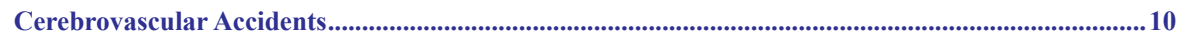

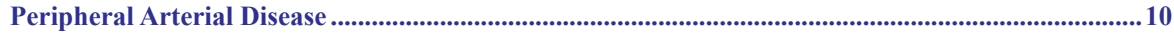

Diabetic Foot ................................................................................................................................................................... 10

Management of Specific Types of T2DM .........................................................................11

Gestational Diabetes Mellitus ........................................................................................................... 11

Diabetes in Older Adults ........................................................................................................ 12

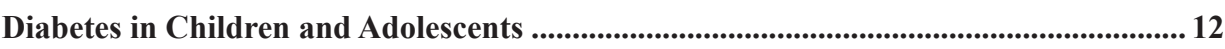

Relevance to Nepal...........................................................................................................12

Conclusion .................................................................................................................................13

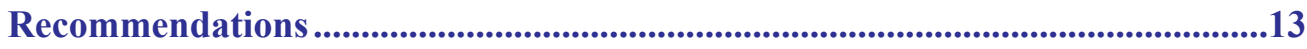

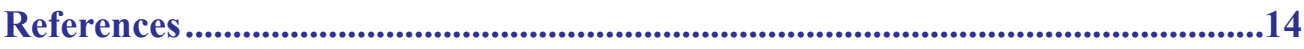




\section{Introduction}

The World Health Organisation (WHO) and International Diabetes Federation (IDF) define Diabetes Mellitus (DM) as a heterogeneous metabolic disorder characterized by disturbed metabolism of carbohydrates, fats and proteins secondary to defective insulin action, secretion, or both. ${ }^{1} \mathrm{DM}$ is a non-communicable disease with a rapidly increasing global prevalence. ${ }^{2}$ One in every ten or 642 million adults will have DM by the year $2040 .{ }^{3} \mathrm{DM}$ has disproportionately affected the Asian population as a consequence of unrivalled socioeconomic development, rapid urbanization and adverse lifestyle changes. ${ }^{4}$ The geographical variation in the burden of DM is also attributed to regional disparity in epigenetics and metabolic risk factors. ${ }^{5}$

The American Diabetes Association (ADA) has classified DM into Type 1 DM (due to autoimmune destruction of the pancreatic beta cells), Type 2 DM (due to progressive diminution of insulin secretion by the pancreatic beta cells), Gestational DM (diagnosed in the second or third trimester of pregnancy, but not prior to gestation) and specific types of DM due to other causes such as monogenic diabetes syndromes (such as neonatal diabetes and maturity-onset diabetes of the young [MODY]), exocrine disorders of the pancreas (such as cystic fibrosis) and drug or chemical induced diabetes (associated with glucocorticoids and antiretroviral drugs). ${ }^{6}$ This guideline will focus on the diagnosis and management of Type 2 DM (T2DM).

\section{Screening for T2DM}

Patients with T2DM may remain asymptomatic for a long period of time prior to clinical diagnosis. ${ }^{7}$ The screening of all asymptomatic adults for T2DM should be started at the age of 25 years. ${ }^{8}$ The risk factors for T2DM are mentioned in Table 1. ${ }^{8,9}$ The screening for T2DM is done by laboratory measurement of venous fasting plasma glucose, random blood glucose or capillary blood glucose if laboratory testing is unavailable.

\section{Table 1: Risk factors for T2DM}

1. Overweight - body mass index $\geq 23 \mathrm{~kg} / \mathrm{m}^{2}$

2. Central obesity - Waist Hip ratio: men $>0.90$, women $>0.85$; Waist circumference: men $>90 \mathrm{~cm}$, women $>80 \mathrm{~cm}$

3. Family history of T2DM

4. Sedentary lifestyle

5. Previously identified impaired fasting glucose (IFG) or impaired glucose tolerance (IGT)

6. History of gestational DM, recurrent fetal loss or delivery of large baby $\geq 3.5 \mathrm{~kg}$

7. Hypertension (blood pressure $>140 / 90 \mathrm{mmHg}$ )

8. Dyslipidaemia

9. Metabolic syndrome (WHO criteria)

10. Cardiovascular disease (Myocardial infarction, angina or stroke) and peripheral arterial disease

11. Polycystic ovarian syndrome

\section{Diagnostic Criteria for T2DM}

The diagnosis of T2DM is based on plasma glucose criteria. Fasting plasma glucose (FPG) and the 2-hour plasma glucose (2-h PG) values determined by 75 gram
Oral Glucose Tolerance Test (OGTT) are indicated for the diagnosis of T2DM. ${ }^{6}$ If one of the FPG, 2-h PG or random plasma glucose tests is positive, the diagnosis of T2DM is to be confirmed with another test subsequently. ${ }^{8}$ Glycated haemoglobin (HbAlc) level should be estimated in a laboratory, ${ }^{6}$ when cost is not an issue. The diagnostic criteria for T2DM endorsed by the ADA 2018 recommendations are listed in Table $2 .{ }^{6}$

\section{Steps for the 75 gm OGTT: ${ }^{10}$}

- Do not eat anything and avoid all drinks besides water before going for testing in the morning

- Blood sample is obtained initially from any vein, fingertip or earlobe to determine the baseline blood sugar level, i.e. FPG level

- Then a solution consisting of $75 \mathrm{~g}$ of anhydrous glucose in $300 \mathrm{ml}$ of water is administered orally

- Blood is drawn again after 2 hours and the blood sugar level is measured, i.e. $2 \mathrm{~h}-\mathrm{PG}$ level

Table 2: Diagnostic criteria for T2DM according to the ADA 2018 recommendations

\begin{tabular}{|l|c|}
\hline Parameter & Criterion \\
\hline FPG level & $\geq 126 \mathrm{mg} / \mathrm{dl}$ \\
\hline 2-h PG level & $\geq 200 \mathrm{mg} / \mathrm{dl}$ \\
\hline HbAlc level* & $\geq 6.5 \%$ \\
\hline Random plasma glucose** & $\geq 200 \mathrm{mg} / \mathrm{dl}$ \\
\hline
\end{tabular}

*In absence of unequivocal hyperglycaemia, results should be confirmed by repeat testing.

**Testing is done in presence of classic symptoms of hyperglycaemia or hyperglycaemic crisis. 


\section{Assessment of Glycaemic Control}

FPG and postprandial plasma glucose (PPG) is measured monthly in capillary or venous blood to assess the current glycaemic status, while the measurement of $\mathrm{HbAlc}$ level is done quarterly to assess the long term glycaemic control. ${ }^{11}$ Glycaemic targets should be customized according to the life expectancy, disease duration, microvascular or macrovascular complications, CV risk factors, comorbid conditions, psychological status and risk for hypoglycaemia. ${ }^{12}$ In adults newly diagnosed with T2DM and absence of significant $\mathrm{CV}$ disease, the goal should be to achieve normoglycaemia. ${ }^{12}$ The target HbAlc level should be $<7 \%$ for adult patients without complications. The target $\mathrm{HbA} 1 \mathrm{c}$ level for older adults should be $7 \%$ to $7.5 \%$. Table 3 provides the equivalent values for $\mathrm{HbAlc}$ level and the capillary plasma glucose level. ${ }^{13}$

Table 3: Equivalent values for HbA1c and capillary plasma glucose

\begin{tabular}{|l|c|c|}
\hline Parameter & Normal & Target \\
\hline HbAlc & $<6.0 \%$ & $<7.0 \%$ \\
\hline $\begin{array}{l}\text { Fasting/pre-meal } \\
\text { capillary plasma } \\
\text { glucose }\end{array}$ & $<100 \mathrm{mg} / \mathrm{dl}$ & $<115 \mathrm{mg} / \mathrm{dl}$ \\
\hline $\begin{array}{l}\text { Post-meal capillary } \\
\text { plasma glucose }\end{array}$ & $<140 \mathrm{mg} / \mathrm{dl}$ & $<160 \mathrm{mg} / \mathrm{dl}$ \\
\hline
\end{tabular}

\section{Monitoring and Follow-up}

The optimal method for monitoring the glycaemic control includes a combination of laboratory confirmed FPG, 2h-PG, HbA1c levels and self-monitored blood glucose (SMBG) level. ${ }^{14}$ The HbA1c level is to be measured at a laboratory certified by the National Glycohaemoglobin Standardization Program (NGSP) that is standardized to the Diabetes Control and Complications Trial (DCCT) assay.

HbA1c level is useful to check the adequacy of the testing schedules and the accuracy of results from SMBG. However, $\mathrm{HbAlc}$ levels should be interpreted with caution among patients with anaemia, diabetic kidney disease, thalassemia and recent blood transfusion. HbAlc level could be estimated every 3 to 6 months depending on the level of glycaemic control. If the patient is unstable, the follow-up can be arranged every 1 to 4 weeks. Earlier follow-up should be arranged during pregnancy or tapering dose of medications related to glycaemic variability. Clinical visits should be scheduled every 3 months for measuring the weight and blood pressure along with annual screening for macrovascular and microvascular complications of T2DM. ${ }^{14}$
SMBG entails monitoring of capillary blood glucose level using an enzyme-specific glucometer. The use of glucometer is particularly suitable for patients on multiple insulin doses or insulin pump therapy. ${ }^{14}$ The application of SMBG is useful for monitoring daily control and to diagnose hypoglycaemic or hyperglycaemic episodes. The frequency of SMBG should be adapted to the glycaemic status, patient's age and stability of T2DM. The SMBG level should be considered in association with $\mathrm{HbAlc}$ and clinical parameters to customize the therapy for T2DM. ${ }^{11}$

\section{Management of T2DM}

\section{Lifestyle Management}

Lifestyle management is a fundamental aspect of care for T2DM. Diabetes self-management education and support (DSMES), medical nutrition therapy (MNT), physical activity, smoking cessation counseling, and psychosocial care are important components of lifestyle management. Patients and healthcare professional should work together on optimizing lifestyle for enhancing diabetes care. ${ }^{15}$

DSMES services incorporate the requirements, goals, and life experiences of individuals with T2DM. They leverage the knowledge, skills, and abilities necessary for optimal diabetes self-care. Individuals with T2DM need to show initiative for participation in physical activities or exercises. All people with T2DM should be counselled against cigarette smoking and consumption of other tobacco products. All individuals with T2DM should also be offered a referral for individualized MNT by a professional dietitian when feasible. ${ }^{15}$

However, the Nepalese food culture consisting of carbohydrate rich meals, limited food options and typical food preparation poses a barrier to dietary management of T2DM. ${ }^{16}$ Dietary advice should be imparted by a trained health professional whenever possible and customized to the patient profile. When this is not possible, the 'Zimbabwe Hand Jive' technique is useful for individuals with T2DM to estimate the food portion sizes..$^{17}$ Alternatively, the 'Diabetes Plate Method' is a guide for planning meals that is endorsed by the ADA. ${ }^{18}$

Overweight or obese individuals should target a weight loss of at least $5 \%$ to $10 \%$, with a regimen customised to individual profile. ${ }^{14}$ On the other hand, weight gain is an important requirement for underweight individuals. Calorie restricted diet is an important dietary recommendation, which depends on the physical activity and nutritional status of individuals with T2DM. The calorie intake should be altered gradually. ${ }^{8}$ Carbohydrates should constitute 
$44 \%-46 \%$ of the total calorie requirement. Protein and fat should account for $15 \%-20 \%$ and $20 \%-35 \%$ of total calorie requirements, respectively. ${ }^{15}$ Fiber rich foods and whole fruits should be consumed in moderation. ${ }^{8}$ The consumption of alcohol and artificial sweeteners should be avoided.

Physical activity is an important pillar for management of T2DM. An exercise program should be customized to individual functionality and disabilities. ${ }^{8}$ Moderate intensity aerobic physical activity is the recommended regimen with at least 30-45 $\mathrm{min} /$ day. Resistance training is recommended at least twice a week, while muscle strengthening activities should be performed $\geq 2$ days per week. ${ }^{14}$ Sleep of 7 to 9 hours duration is recommended at night.

The diagnosis of T2DM is a stressful life event and education on stress management forms an important aspect of the holistic management strategy. The patient with T2DM should undergo behavioral modification to develop positive attitude and healthy lifestyle. Specific guidance should be provided for developing coping skills, fostering family support and inculcation of healthy workplace environment. ${ }^{8}$ Table 4 lists the content and structure of a diabetic education programme. ${ }^{17}$

\section{Table 4: Structure of a diabetic education programme}

\begin{tabular}{|c|c|c|}
\hline Session & Title & Content \\
\hline 1 & $\begin{array}{l}\text { Understanding } \\
\text { your diabetes }\end{array}$ & $\begin{array}{l}\text { - What constitutes diabetes? } \\
\text { - Common myths and facts }\end{array}$ \\
\hline 2 & $\begin{array}{l}\text { Understanding } \\
\text { your } \\
\text { medication }\end{array}$ & \begin{tabular}{|l} 
- \\
Using medication to control \\
diabetes \\
- Considerations when using \\
medications \\
- Dealing with episodes of \\
low blood glucose
\end{tabular} \\
\hline 3 & $\begin{array}{l}\text { Living a } \\
\text { healthy lifestyle }\end{array}$ & $\begin{array}{l}\text { - What is a healthy food? } \\
\text { - What are sensible or healthy } \\
\text { portion sizes? } \\
\text { - } \quad \text { Tow to prepare food? } \\
\text { snings of meals and } \\
\text { - Physical activity } \\
\text { - Lifestyle issues such as } \\
\text { smoking, stress, alcohol }\end{array}$ \\
\hline 4 & $\begin{array}{l}\text { Avoiding } \\
\text { complications }\end{array}$ & $\begin{array}{l}\text { - The dangers of high blood } \\
\text { glucose } \\
\text { - Recognising and controlling } \\
\text { high blood glucose } \\
\text { - What medical assessments } \\
\text { need to be done to } \\
\text { effectively identify and } \\
\text { prevent complications and } \\
\text { when these should be done? }\end{array}$ \\
\hline
\end{tabular}

\section{Pharmacological Management}

Most patients do not achieve the treatment goals with lifestyle management alone, which necessitates the use of an anti-hyperglycaemic agent (AHA). Metformin is the preferred first-line oral therapy in absence of contraindications (Table 5). Metformin monotherapy along with lifestyle interventions is prescribed initially to many patients with T2DM. However, early combination therapy is preferable to prolonged monotherapy for achieving glycaemic targets. If $\mathrm{FPG}>200 \mathrm{mg} / \mathrm{dl}$ at diagnosis then initiate dual therapy; and if FPG $>300 \mathrm{mg} /$ $\mathrm{dl}$ consider dual/triple therapy that may include insulin. Therapy with insulin may also be considered as first line therapy for T2DM patients with HbA1c level $>10 \%$ or random blood sugar $>300 \mathrm{mg} / \mathrm{dl} .{ }^{14}$ Concentrated insulin preparations are indicated in large doses for patients with signs of insulin resistance. ${ }^{19}$ Figure 1 depicts the treatment algorithm using AHAs for customized therapy of T2DM.

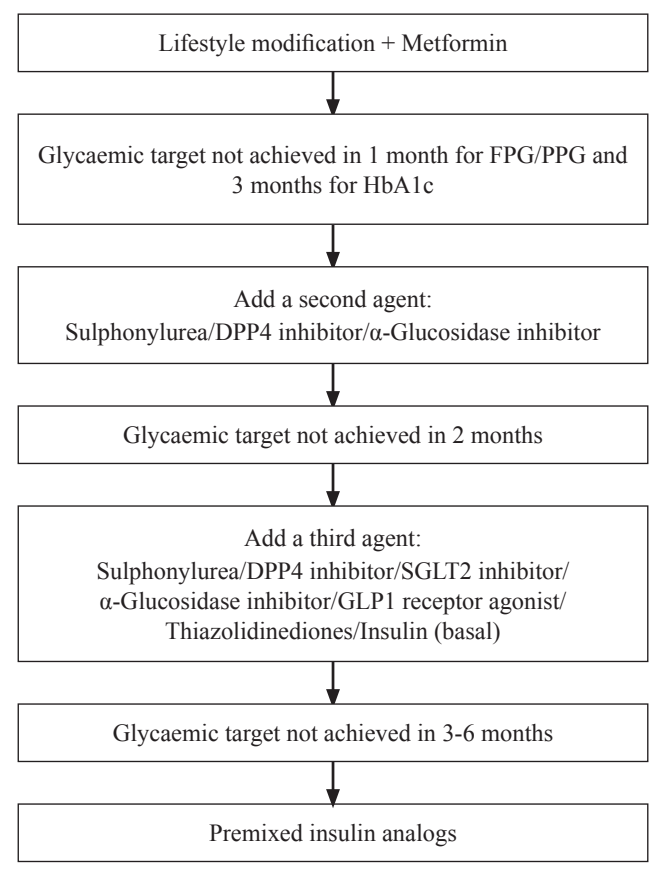

Figure 1: Algorithm for initiation of treatment with AHAs

DPP4, dipeptidyl peptidase 4; FPG, fasting plasma glucose; GLP1, glucagon like peptide 1; HbA1c, glycated haemoglobin; PPG, postprandial plasma glucose; SGLT2, sodium glucose cotransporter 2 . 
NEPAT

\begin{tabular}{|c|c|c|c|c|}
\hline Class of drug & Drug compound & Advantages & Disadvantages & Contraindications \\
\hline Biguanides & - Metformin & $\begin{array}{l}\text { - Extensive experience } \\
\text { - No hypoglycaemia } \\
\text { - Reduced } \\
\text { cardiovascular events } \\
\text { - Decreases insulin } \\
\text { resistance }\end{array}$ & $\begin{array}{l}\text { - Gastrointestinal side } \\
\text { effects } \\
\text { - Vitamin B12 deficiency } \\
\text { - Weight loss } \\
\text { - Lactic acidosis (rare) }\end{array}$ & $\begin{array}{l}\text { - Critically ill } \\
\text { - Dehydration } \\
\text { - Liver failure } \\
\text { - Chronic kidney disease } \\
\text { with glomerular filtration } \\
\text { rate (GFR) of }<30 \mathrm{ml} / \mathrm{min}\end{array}$ \\
\hline Sulphonylureas & $\begin{array}{l}\text { - Glibenclamide } \\
\text { - Glipizide } \\
\text { - Gliclazide } \\
\text { - Glimepiride }\end{array}$ & $\begin{array}{l}\text { - Extensive experience } \\
\text { - Reduced microvascular } \\
\text { risk }\end{array}$ & $\begin{array}{l}\text { - Hypoglycaemia } \\
\text { - Weight gain } \\
\text { - Hematological changes } \\
\text { (agranulocytosis, } \\
\text { hemolysis - rare) }\end{array}$ & $\begin{array}{l}\text { - Severe CV comorbidity } \\
\text { - Sulfonamide allergy } \\
\text { - Severe renal failure } \\
\text { - Elderly patients } \\
\text { - Hypoglycaemia prone } \\
\text { patients }\end{array}$ \\
\hline Meglitinides & - Repaglinide & 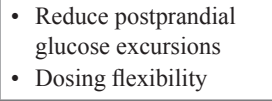 & $\begin{array}{l}\text { - Hypoglycaemia } \\
\text { - Weight gain }\end{array}$ & \\
\hline Thiazolidinediones & - Pioglitazone & $\begin{array}{l}\text { - No hypoglycaemia } \\
\text { - Durability } \\
\text { - Potentially reduced } \\
\text { cardiovascular events } \\
\text { - Decreases insulin } \\
\text { resistance }\end{array}$ & $\begin{array}{l}\text { - Weight gain } \\
\text { - Edema } \\
\text { - Bone fractures } \\
\text { (osteoporosis) } \\
\text { - Bladder cancer } \\
\text { - Loss of contraceptive } \\
\text { effect in females }\end{array}$ & $\begin{array}{l}\text { - Congestive heart failure } \\
\text { - Liver failure } \\
\text { - Renal failure }\end{array}$ \\
\hline $\begin{array}{l}\alpha \text {-Glucosidase } \\
\text { inhibitors }\end{array}$ & $\begin{array}{l}\text { - Acarbose } \\
\text { - Voglibose }\end{array}$ & $\begin{array}{l}\text { - No hypoglycaemia } \\
\text { - Reduced postprandial } \\
\text { glucose excursions } \\
\text { - Reduced } \\
\text { cardiovascular events } \\
\text { - Non-systemic effect } \\
\text { - Useful for prediabetes }\end{array}$ & $\begin{array}{l}\text { - Gastrointestinal side } \\
\text { effects }\end{array}$ & $\begin{array}{l}\text { - Intestinal disorder } \\
\text { - Renal failure }\end{array}$ \\
\hline DPP-4 inhibitors & $\begin{array}{l}\text { - Sitagliptin } \\
\text { - Linagliptin }\end{array}$ & $\begin{array}{l}\text { - Reduced risk of } \\
\text { hypoglycaemia } \\
\text { - Well tolerated }\end{array}$ & $\begin{array}{l}\text { - Upper respiratory tract } \\
\text { infection } \\
\text { - Acute pancreatitis (rare) }\end{array}$ & \\
\hline SGLT-2 inhibitors & $\begin{array}{l}\text { - Canagliflozin } \\
\text { - Dapagliflozin } \\
\text { - Empagliflozin }\end{array}$ & $\begin{array}{l}\text { - No hypoglycaemia } \\
\text { - Weight loss } \\
\text { - Reduced blood } \\
\text { pressure } \\
\text { - Effective at all stages } \\
\text { of T2DM }\end{array}$ & $\begin{array}{l}\text { - } \text { Genitourinary } \\
\text { infections } \\
\text { - Polyuria } \\
\text { - Dehydration } \\
\text { - Diabetic ketoacidosis } \\
\text { (Dapagliflozin) } \\
\text { - Fracture risk } \\
\text { (Canagliflozin) }\end{array}$ & $\begin{array}{l}\text { - Chronic kidney disease } \\
\text { - Recurrent urinary tract } \\
\text { infections }\end{array}$ \\
\hline
\end{tabular}

\section{Oral AHAs}

Currently, the oral AHAs available for treatment of T2DM include biguanides, sulphonylureas, meglitinides, thiazolidinediones, $\alpha$-glucosidase inhibitor, dipeptidyl peptidase-4 (DPP-4) inhibitors and sodium-glucose cotransporter-2 (SGLT-2) inhibitors (Table 5). Metformin remains the first line drug for T2DM due to its ability to prevent microvascular or macrovascular complications and lower insulin resistance. ${ }^{20}$ Sulphonylureas can be the drugs of second choice given that it is cheaper and available. When a patient is at risk for hypoglycaemia and weight gain, DPP-4 inhibitors are the second choice drugs, if cost permits. Meglitinides are also insulin secretagogues, but they have lower risk of hypoglycaemia and require more frequent dosing when compared to sulphonylureas. SGLT-2 inhibitors are associated with weight loss and reduction of blood pressure. ${ }^{21} \alpha$-Glucosidase inhibitors are used for treatment of T2DM characterised by postprandial hyperglycaemia. Thiazolidinediones will be used when not contraindicated. 


\section{Injectable AHAs}

Injectable insulins and glucagon-like peptide-1 (GLP-1) receptor agonists are indicated for glycaemic control in patients with T2DM. The injectable AHAs for treatment of T2DM are listed in Table 6. Insulins are indicated for treatment of T2DM during acute illness, critical illness, pregnancy, perioperative period, diabetic ketoacidosis, resistant hyperglycaemia, glucotoxicity and myocardial infarction.

Basal insulin enables uniform insulin coverage over 24 hours. Although basal insulin with addition of oral AHAs may meet the requirements of most patients with T2DM, some may require additional prandial insulin therapy with shorter-acting insulins. Regular insulin may be administered 30 minutes before the meal or rapidacting insulin analogues such as insulin lispro or insulin aspart may be administered just before meals. ${ }^{22}$
The use of basal insulin at night with concomitant oral AHAs, would suppress the hepatic output of glucose and reduce the fasting hyperglycaemia. Early insulin initiation is strongly recommended for patients with established diagnosis of T2DM after a trial of 3 oral AHAs fails to achieve glycaemic control within 2 to 3 months. When insulin is to be added for treatment of T2DM that is not controlled with oral AHAs, addition of basal insulin (glargine, detemir, degludec, NPH) is the simplest method of starting insulin therapy. ${ }^{23,24}$ In T2DM patients, it is advisable to continue metformin along with insulin. However, it is advisable not to give sulphonylureas with prandial insulin..$^{25}$

Basal plus regimen is characterised by addition of prandial insulin, beginning with the main meal that influences postprandial glucose levels in addition to basal insulin and OHA. Basal plus regimen is indicated in

\begin{tabular}{|c|c|c|c|}
\hline Class of drug & Drug compound & Advantages & Disadvantages \\
\hline Insulins & $\begin{array}{l}\text { - Insulin Analogs: } \\
\text { 1. Rapid acting: } \\
\text { a. Aspart } \\
\text { b. Glulisine } \\
\text { c. Lispro } \\
\text { 2. Long acting: } \\
\text { a. Insulin detemir } \\
\text { b. Inulin glargine } \\
\text { - Human Insulins: } \\
\text { 1. Fast acting: } \\
\text { a. Regular insulin } \\
\text { 2. Long acting: } \\
\text { a. Neutral Protamine } \\
\quad \text { Hagedorn (NPH) } \\
\text { Pre-Mixed Insulins: } \\
\text { 1. Human regular insulin } \\
\text { with NPH } \\
\text { a. } 30 / 70 \text { Regular/NPH } \\
\text { 2. Rapid acting insulin } \\
\text { analog with NPH } \\
\text { a. } 30 / 70 \text { Aspart/NPH } \\
\text { b. } 25 / 75 \text { Lispro/NPH } \\
\text { c. } 50 / 50 \text { Lispro/ NPH } \\
\text { Regular insulin }\end{array}$ & $\begin{array}{ll}\text { - } & \text { Nearly universal response } \\
\text { - } & \text { Theoretically unlimited } \\
\text { efficacy } \\
\text { - } & \text { Reduced microvascular risk }\end{array}$ & $\begin{array}{ll}\text { - } & \text { Hypoglycaemia } \\
\text { - } & \text { Weight gain } \\
\text { - } & \text { Injectable } \\
\text { - } & \text { Patient reluctance } \\
\text { - } & \text { Training requirements }\end{array}$ \\
\hline $\begin{array}{l}\text { GLP-1 receptor } \\
\text { agonists }\end{array}$ & $\begin{array}{ll}\text { - } & \text { Liraglutide } \\
\text { - } & \text { Exenatide } \\
\text { - } & \text { Liraglutide } \\
\text { - } & \text { Lixisenatide } \\
\text { - } & \text { Albiglutide } \\
\text { - } & \text { Dulaglutide } \\
\text { - } & \text { Semaglutide }\end{array}$ & $\begin{array}{ll}\text { - } & \text { No hypoglycaemia } \\
\text { - } & \text { Weight loss } \\
\text { - } & \text { Reduced postprandial glucose } \\
\text { excursions } \\
\text { - } & \text { Reduction in CV risk factors }\end{array}$ & $\begin{array}{l}\text { - } \text { Gastrointestinal side effects } \\
\text { - Increased heart rate } \\
\text { - } \text { Potential acute pancreatitis } \\
\text { - } \text { Injectable } \\
\text { - } \text { Training requirements } \\
\text { - } \\
\text { Expensive }\end{array}$ \\
\hline
\end{tabular}




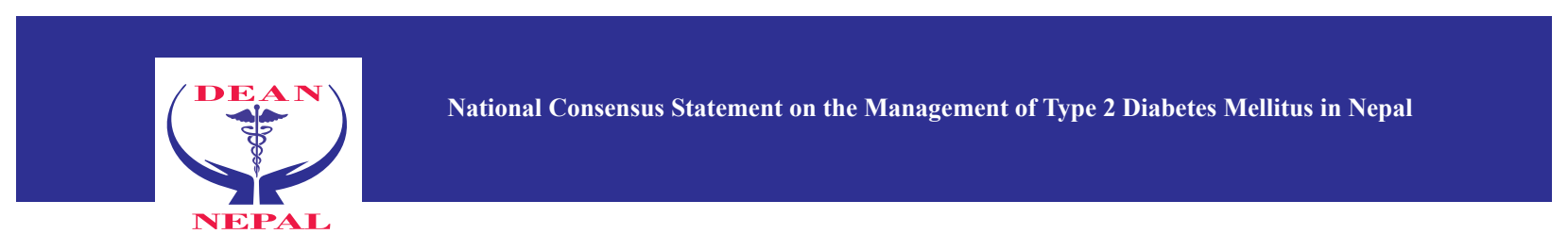

those patients treated with basal insulin with or without OHA who do not reach the FPG, PPG and HbAlc goals. Moreover, patients with uncontrolled hyperglycaemia or those with limitations for using high doses of basal insulin are appropriate candidates for basal plus regimen. ${ }^{22}$

Basal bolus regimen mimics the physiologic insulin secretion that involves basal insulin combined with bolus or prandial rapid-acting insulin before each meal. This regimen requires 3 or 4 daily injections, but offers flexibility with respect to the meal timings, size and composition. Basal bolus regimen is ideal for young adults and pregnant women. ${ }^{26}$ Insulin pumps are indicated for intensive treatment and hypoglycaemia unawareness. Intensification of insulin therapy should be accompanied by glucose monitoring and counselling for hypoglycaemia as well as its care. ${ }^{27}$

Premixed insulin analogues consist of rapid-acting and intermediate-acting insulin analogues. They were developed to more closely mimic physiological endogenous insulin secretion and meet the needs of patients who require both basal and prandial insulin but wish to limit the number of daily injections. ${ }^{28}$ Premixed insulin analogues can be started once daily to cover the biggest meal of the day instead of basal only Insulin therapy. Premixed insulin analogues have more physiological pharmacokinetic and therapeutically more desirable pharmacodynamic profiles than premixed human insulins. Consequently, postprandial glycaemic control is better with premixed insulin analogues than with premixed human insulin. ${ }^{29}$ However, when cost is an issue, all human insulin Premix, Regular and NPH can be a good choice.

\section{Management of Complications of T2DM}

The acute and chronic complications of T2DM account for the morbidity and mortality associated with T2DM. The acute complications of T2DM include Diabetic ketoacidosis, Hyperosmolar hyperglycaemic state and hypoglycaemia. ${ }^{30}$ The chronic complications of T2DM may be classified as microvascular and macrovascular complications. The microvascular complications include nephropathy, retinopathy and neuropathy. Coronary heart disease (CHD), peripheral arterial disease (PAD), and cerebrovascular accidents (CVA) are the macrovascular complications of T2DM. ${ }^{31}$ Comorbidities such as obesity, hypertension and dyslipidaemia accentuate the risk of cardiovascular complications in patients with T2DM. ${ }^{32}$

\section{Acute Complications of T2DM}

Diabetic Ketoacidosis

Diabetic ketoacidosis (DKA) is an acute condition characterised by uncontrolled hyperglycaemia, metabolic acidosis, and increased total body ketone concentration. ${ }^{33}$ The precipitating factors for DKA include infections, CV disease, inadequate insulin therapy, medical illness and non-compliance with therapy. ${ }^{34}$ The overall mortality is $<1 \%$ among adults with DKA, but a mortality rate $>5 \%$ has been reported in the elderly and those with life-threatening comorbidities. $^{33}$

The diagnostic criteria for DKA is mentioned in Table 7. The therapeutic goals for treatment of DKA include improving circulatory volume, reducing serum glucose, addressing the electrolyte imbalances, management of acute precipitating events, normalising plasma osmolality,

\begin{tabular}{|c|c|c|c|}
\hline \multirow{2}{*}{ Parameter } & \multicolumn{3}{|c|}{ DKA Criteria } \\
\hline & Mild & Moderate & Severe \\
\hline Plasma glucose (mg/dl) & $>250$ & $>250$ & $>250$ \\
\hline Arterial $\mathrm{Ph}$ & $7.25-7.30$ & $7.00-<7.24$ & $<7.00$ \\
\hline Serum bicarbonate $(\mathrm{mEq} / \mathrm{l})$ & $15-18$ & $10-<15$ & $<10$ \\
\hline Urine ketones* & Positive & Positive & Positive \\
\hline Serum ketones* & Positive & Positive & Positive \\
\hline Effective serum osmolality $(\mathrm{mOsm} / \mathrm{kg})$ & Variable & Variable & Variable \\
\hline Anion gap & $>10$ & $>12$ & $>12$ \\
\hline Altered sensorium & Alert & Alert/drowsy & Stupor/coma \\
\hline
\end{tabular}

*Nitroprusside reaction method. 
enhancing tissue perfusion, and facilitating the clearance of serum and urine of ketones at a steady rate. ${ }^{34}$

Hyperosmolar Hyperglycaemic State

Hyperosmolar hyperglycaemic state (HHS) is another important acute hyperglycaemic complication of T2DM. HHS is clinically differentiated from DKA only by the severity of dehydration and the degree of metabolic acidosis. ${ }^{35}$ However, HHS occurs mostly in older adults with fluid intake issues and has a mortality rate of $5 \%$ to $16 \%{ }^{36}$ HHS is characterised by presence of altered sensorium without coma and clinical ketosis to variable degrees. HHS may occur secondary to precipitating factors such as acute illness, drugs or previously undiagnosed T2DM. The diagnostic parameters for HHS are mentioned in Table 8. ${ }^{34}$

\begin{tabular}{|l|c|}
\hline \multicolumn{2}{|l|}{ Table 8: Diagnostic criteria for HHS } \\
\hline Parameter & HHS Criteria \\
\hline Plasma glucose $(\mathrm{mg} / \mathrm{dl})$ & $>600$ \\
\hline Arterial Ph & $>7.30$ \\
\hline Serum bicarbonate (mEq/l) & $>15$ \\
\hline Urine ketones* & Small \\
\hline Serum ketones* & Small \\
\hline $\begin{array}{l}\text { Effective serum osmolality } \\
\text { (mOsm/kg) }\end{array}$ & $>320$ \\
\hline Anion gap & $<12$ \\
\hline Altered sensorium & Stupor/Coma \\
\hline
\end{tabular}

*Nitroprusside reaction method.

The treatment of HHS, as with DKA, involves treatment of dehydration and hyperglycaemia. The serum osmolality should be carefully monitored in order to avoid complications of rapid overcorrection. Aggressive correction of dehydration with intravenous fluids till osmolality stops declining is recommended. ADA recommends maintaining serum glucose concentrations between 250 to $300 \mathrm{mg} / \mathrm{dL}$ by administration of intravenous insulin. Patients with HHS may also have depleted potassium stores which need to be restored by supplementing potassium. ${ }^{36}$

\section{Hypoglycaemia}

Hypoglycaemia is a major limiting factor in hyperglycaemic management. ${ }^{37}$ Serious or clinically significant hypoglycaemia is indicated by blood glucose $<54 \mathrm{mg} / \mathrm{dL}$ detected by SMBG, CGM (for at least $20 \mathrm{~min}$ ), or laboratory measurement of plasma glucose that is sufficiently low. However, a glucose alert value of $\leq 70 \mathrm{mg} / \mathrm{dL}$ is related to symptomatic hypoglycaemia and is useful for therapeutic dose adjustment of hypoglycaemic agents in routine care. ${ }^{37}$
Glucose or another carbohydrate is the preferred treatment for the conscious individual with blood glucose $\leq 70 \mathrm{mg} / \mathrm{dL}$. When SMBG is low, blood sample should be sent for laboratory confirmation if feasible. If SMBG shows continued hypoglycaemia after fifteen minutes of treatment, the treatment should be repeated. Once SMBG returns to normal, the individual should consume a complex meal or snack to avoid recurrence of hypoglycaemic episode. If the patient is unconscious, needs assistance or has severe hypoglycaemia, then intravenous dextrose is administered. Episodes of hypoglycaemia should mandate re-evaluation of the treatment regimen. ${ }^{37}$ If the hypoglycaemic person is on $\alpha$-glucosidase inhibitors, treat with glucose.

\section{Microvascular Complications of T2DM}

\section{Diabetes Kidney Disease}

Diabetes Kidney disease (DKD) manifests in $20-40 \%$ of patients with T2DM at diagnosis and contributes to the development of end-stage renal disease. All patients with T2DM and comorbid hypertension should undergo annual assessment of urinary albumin, albumin-creatinine ratio and estimated glomerular filtration rate. The treatment for glycaemic control and blood pressure should be optimized for reducing the risk or slowing the progression of DKD. ${ }^{38}$

Nutrition should be the focus of DKD management, with limitation of dietary protein intake to $0.8 \mathrm{~g} / \mathrm{kg}$ of body weight/day in people with non-dialysis dependent DKD. ${ }^{38}$ The glycaemic control in DKD patients is assessed by plasma blood glucose level and treatment decisions are based on SMBG. ${ }^{39}$ The drug-specific and patient factors to consider when selecting AHAs in adults with DKD are mentioned in Table 9. ${ }^{19}$

In DKD patients with comorbid hypertension, angiotensin converting enzyme inhibitors (ACEIs) or angiotensin receptor blockers (ARBs) are recommended with periodic monitoring of serum creatinine and potassium levels. ACEIs or ARBs are also strongly recommended for those with urinary albumin-to-creatinine ratio $\geq 300 \mathrm{mg} / \mathrm{g}$ creatinine and/or estimated glomerular filtration rate (eGFR) $<60 \mathrm{~mL} / \mathrm{min} / 1.73 \mathrm{~m}^{2}$. Close monitoring of serum potassium levels and kidney function are indicated if the use of ACEIs and ARBs is continued in patients with DKD due to the attendant risks of hyperkalemia and acute kidney injury. ${ }^{39}$ Moreover, the evaluation and management of complications associated with DKD should be initiated among those with eGFR $<60 \mathrm{~mL} / \mathrm{min} / 1.73 \mathrm{~m}^{2}$. Referral for evaluation for renal replacement therapy is indicated if eGFR $<30 \mathrm{~mL} / \mathrm{min} / 1.73 \mathrm{~m}^{2}$ or when needed. ${ }^{38}$ 


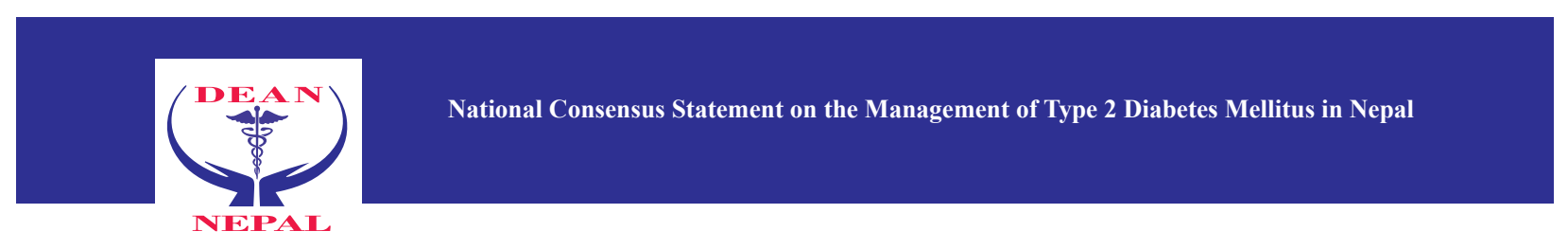

\begin{tabular}{|c|c|c|}
\hline \multirow{2}{*}{ AHAs } & \multicolumn{2}{|r|}{ Renal effects } \\
\hline & Progression of DKD & Dosing/use consideration \\
\hline Metformin & Neutral & $\begin{array}{l}\text { - } \quad \text { No dose adjustment if eGFR }>45 \\
\text { - } \quad \text { Do not initiate or assess risk/benefit if eGFR } 30-45 \\
\text { - } \quad \text { Contraindicated with eGFR }<30\end{array}$ \\
\hline $\begin{array}{l}\text { Sulphonylureas } \\
\left(2^{\text {nd }} \text { generation }\right)\end{array}$ & Neutral & $\begin{array}{l}\text { - Glibenclamide: not recommended in renal impairment } \\
\text { - Glipizide: initiate conservatively at } 2.5 \mathrm{mg} \text { daily to avoid hypoglycaemia } \\
\text { - Glimepiride: initiate conservatively at } 1 \mathrm{mg} \text { daily to avoid hypoglycaemia }\end{array}$ \\
\hline Meglitinides & & $\begin{array}{l}\text { - Repaglinide: initiate conservatively at } 0.5 \mathrm{mg} \text { with meals if eGFR }<30 \\
\text { - Nateglinide: initiate conservatively at } 60 \mathrm{mg} \text { with meals if eGFR }<30\end{array}$ \\
\hline Thiazolidinedione & Neutral & $\begin{array}{l}\text { - } \quad \text { No dose adjustment required } \\
\text { - Generally not recommended in renal impairment due to potential for fluid } \\
\text { retention }\end{array}$ \\
\hline$\alpha$-Glucosidase inhibitors & & $\begin{array}{l}\text { - Acarbose: Avoid if eGFR }<30 \\
\text { - } \quad \text { Miglitol: Avoid if eGFR }<25\end{array}$ \\
\hline SGLT-2 inhibitors & $\begin{array}{l}\text { Benefit: canagliflozin, } \\
\text { empagliflozin }\end{array}$ & $\begin{array}{l}\text { - Canagliflozin: not recommended with eGFR }<45 \\
\text { - Dapagliflozin: not recommended with eGFR }<60 \text {; contraindicated with } \\
\text { eGFR }<30 \\
\text { - Empagliflozin: contraindicated with eGFR }<30\end{array}$ \\
\hline DPP-4 inhibitors & Neutral & $\begin{array}{l}\text { - Renal dose adjustment required; can be used in renal impairment } \\
\text { - } \quad \text { Linagliptin: No dose adjustment required }\end{array}$ \\
\hline Insulin & Neutral & $\begin{array}{l}\text { - Lower insulin doses required with a decrease in eGFR; titrate per clinical } \\
\text { response }\end{array}$ \\
\hline GLP-1 receptor agonists & Benefit: Liraglutide & $\begin{array}{l}\text { - Increased risk of side effects in patients with renal impairment } \\
\text { - Liraglutide: No specific dose adjustment recommended by the } \\
\text { manufacturer; limited experience in patients with severe renal impairment }\end{array}$ \\
\hline
\end{tabular}

Diabetic Retinopathy

Diabetic retinopathy (DR) is the most frequent cause of new onset of blindness among adults aged 20-74 years. DR is a vascular complication, the prevalence of which is strongly related to both the duration of T2DM as well as the level of glycaemic control. Consequently, optimal glycaemic control is necessary for reducing the risk or slowing the progression of DR. ${ }^{38}$ An opportunistic screening model can be adopted for detection of other complications of T2DM when at risk patients present for screening or management of DR. ${ }^{40}$

An initial dilated and comprehensive eye examination should be conducted by an ophthalmologist at the time of the diagnosis of T2DM. ${ }^{38}$ Screening for diabetic retinopathy should involve a complete ophthalmic examination with refractory visual activity and fundus photography. Screening in limited resource setting should entail a visual acuity exam and retina examination for adequate DR classification. Table 10 lists the follow-up schedule and the management strategy according to the severity of DR..$^{38,41}$

\begin{tabular}{|l|l|}
\hline \multicolumn{2}{|l|}{ Table 10: Management of DR according to severity } \\
\hline $\begin{array}{l}\text { Diabetic retinopathy } \\
\text { finding }\end{array}$ & Management strategy \\
\hline No apparent DR & Repeat examination annually \\
\hline Mild non-proliferative DR & Repeat examination annually \\
\hline $\begin{array}{l}\text { Moderate non-proliferative } \\
\text { DR }\end{array}$ & $\begin{array}{l}\text { Repeat examination within } \\
\text { 6-12 hours }\end{array}$ \\
\hline $\begin{array}{l}\text { Severe non-proliferative } \\
\text { DR }\end{array}$ & $\begin{array}{l}\text { Pan-retinal laser } \\
\text { photocoagulation therapy }\end{array}$ \\
\hline Proliferative DR & $\begin{array}{l}\text { Pan-retinal laser } \\
\text { photocoagulation therapy/intra- } \\
\text { vitreal injections of anti-VEGF } \\
\text { agents }\end{array}$ \\
\hline Diabetic macular edema & $\begin{array}{l}\text { Laser/intra-vitreal injections of } \\
\text { anti-VEGF agents/steroids }\end{array}$ \\
\hline
\end{tabular}

VEGF, Vascular endothelial growth factor 
Diabetic Neuropathy

Diabetic neuropathy is the most common complication of T2DM. It consists of heterogeneous disorders with diverse clinical manifestations. Diabetic peripheral neuropathy (DPN) may be asymptomatic in up to $50 \%$ of cases. Consequently, all patients with T2DM should be assessed annually for DPN using medical history and clinical evaluation. Numbness and loss of protective sensation is a risk factor for diabetic foot ulceration. Hence, all patients with DPN should be screened for foot ulcer and evaluated for risk of amputation using the annual $10 \mathrm{gm}$ monofilament testing. Patients with DPN should be assessed at the time of diagnosis of T2DM followed by repeat annual evaluations. People with painful DPN are initially recommended treatment with pregabalin or duloxetine. ${ }^{38}$

Diabetic autonomic neuropathy (DAN) is another important entity, the detection of which by history and physical examination may improve symptoms, decrease the sequalae and improve the quality of life. Cardiac autonomic neuropathy is an independent risk factor for cardiovascular mortality in patients with T2DM. Gastrointestinal neuropathies may lead to variable gastrointestinal manifestations such as esophageal dysmotility, constipation and diarrhoea. DAN may also contribute to genitourinary disturbances, including erectile dysfunction among men and sexual dysfunction among women. Assessment for DAN is indicated in patients with microvascular complications. The treatment of DAN varies according to organ system involved. Severe cases of diabetic neuropathy should be referred to neurologists for appropriate management. ${ }^{38}$

\section{Macrovascular Complications of T2DM}

\section{Coronary Heart Disease}

CHD is the most well-established complication of T2DM, with two- to threefold increased CHD risk among T2DM subjectscomparedwithnondiabeticsubjects. ${ }^{42}$ Consequently, $\mathrm{T} 2 \mathrm{DM}$ is recognised as the "CHD equivalent." ${ }^{\text {43 }}$ Routine screening for CHD is not recommended in asymptomatic patients as long as atherosclerotic cardiovascular disease (ASCVD) risk factors such as hypertension, hyperglycaemia and dyslipidaemia are being treated. Occurrence of atypical cardiac symptoms, electrocardiogram abnormalities, PAD or CVA should be followed by battery of investigations for CHD in patients with T2DM. ${ }^{44}$

ACEIs or ARBs are indicated in patients with established ASCVD, while $\beta$-blockers are indicated for secondary prevention of CHD. Aspirin therapy (75-162 mg/day) may be considered as a primary or secondary prevention strategy in people with T2DM. Statin therapy of high and moderate intensity is recommended for T2DM patients with and without ASCVD, respectively. Moreover, lifestyle management forms the crux of cardiovascular risk management among people with T2DM. ${ }^{44}$

Antihyperglycaemic therapy should begin with lifestyle management and metformin. AHAs such as empagliflozin and liraglutide that are proven to reduce major adverse cardiovascular events and cardiovascular mortality, can be introduced after considering drug-specific and patient factors (Table 11). However, do not use metformin if eGFR remains $<45 \mathrm{~mL} / \mathrm{min}$ in T2DM outpatients with stable congestive heart failure (CHF), but not in unstable or hospitalized cases. ${ }^{19}$

\begin{tabular}{|l|l|l|}
\hline \multirow{2}{*}{ Table 11: AHAs in adults with established ASCVD and CHF } \\
& \multicolumn{2}{|c|}{ CSCVD } \\
\cline { 2 - 3 } & \multicolumn{2}{|c|}{ Cardiovascular effects } \\
\hline Metformin & Potential benefit & Neutral \\
\hline Sulphonylureas $\left(2^{\text {nd }}\right.$ generation$)$ & Neutral & Neutral \\
\hline Thiazolidinedione & Potential benefit: Pioglitazone & Increased risk \\
\hline SGLT-2 inhibitors & Benefit: canagliflozin, empagliflozin & Benefit: canagliflozin, empagliflozin \\
\hline DPP-4 inhibitors & Neutral & Potential risk: saxagliptin, alogliptin \\
\hline Insulin & Neutral & Neutral \\
\hline GLP-1 receptor agonists* & $\begin{array}{l}\text { Benefit: Liraglutide } \\
\text { Neutral: Lixisenatide, exenatide extended release }\end{array}$ & Neutral \\
\hline
\end{tabular}

*In a meta-analysis, dulaglutide did not show excess cardiovascular events in patients with type 2 diabetes. 75 The ongoing CV outcomes study, Researching CV Events with a Weekly Incretin in Diabetes (REWIND), will further assess CV safety of dulaglutide. ${ }^{76}$ 


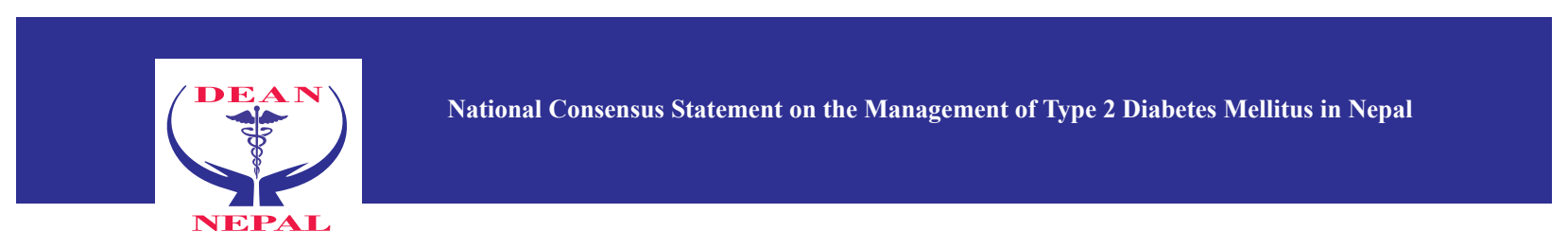

Cerebrovascular Accidents

CVAs occur in about $20 \%$ to $40 \%$ of patients with T2DM. The main clinical manifestations of CVA include asymptomatic cerebral atherosclerosis, stroke, cerebral small vessel disease and acute cerebral vascular disease. ${ }^{47}$ The risk of CVA is 2-6 times more magnified in patients with T2DM, with younger individuals and those with comorbid hypertension being particularly susceptible to developing acute ischaemic stroke. This is attributed to increased brain oedema, neovascularization and altered vascular reactivity as well as tone secondary to chronic hyperglycaemia. ${ }^{48}$

Correction of hyperglycaemia during an episode of acute brain ischemia may improve clinical outcomes by limiting the brain injury. Intravenous insulin is the only effective method to lower hyperglycaemia to near $100 \mathrm{mg} / \mathrm{dL}$ within 4 to 5 hours. Subcutaneous insulin protocols may maintain blood glucose levels below $200 \mathrm{mg} / \mathrm{dL}$ a majority of the time in most patients, especially if basal insulin is added. ${ }^{49}$ There are no major clinical trials that have investigated the specific stroke prevention strategies in people with T2DM. ${ }^{50}$

\section{Peripheral Arterial Disease}

PAD is an important macrovascular complication of T2DM characterised by atherosclerosis of the lower extremity arteries. PAD occurs earlier and is often more severe and diffuse in patients with T2DM. PAD is associated with increased risk of claudication, ischemic ulcers and gangrene. It is also a marker for generalized atherosclerosis and a prognostic factor for cardiovascular and cerebrovascular ischemic events. ${ }^{51}$

Early diagnosis and treatment of PAD in patients with T2DM is important for reducing the risk of cardiovascular events as well as long-term disability, and for improving the quality of life..$^{52}$ The diagnosis of PAD in patients with T2DM is indicated by a history of decreased walking speed, leg fatigue and intermittent claudication. The assessment of the pedal pulses and ankle-brachial index testing should be performed in patients with symptoms or signs of PAD. ${ }^{38}$ Following the confirmation of the diagnosis of PAD, a multi-faceted treatment approach that entails aggressive risk-factor modification, antiplatelet therapy, and revascularization procedures is recommended. ${ }^{53}$ Cilostazol is the first line therapy for PAD since it improves symptoms as well as the quality of life. ${ }^{54}$

\section{Diabetic Foot}

Patients with T2DM commonly develop foot ulcers and undergo amputations secondary to DPN and PAD. The other risk factors associated with diabetic foot include poor glycaemic control, cigarette smoking, foot deformities, preulcerative callus or corn, history of foot ulcer, amputation, visual impairment and diabetic nephropathy. ${ }^{38}$

A multidisciplinary approach is indicated for T2DM patients with foot ulcers and high-risk feet. Patients with T2DM should undergo an annual comprehensive foot evaluation to identify the aforementioned risk factors. ${ }^{38}$ All patients with T2DM should have their feet inspected at every visit. The examination may include skin inspection, assessment of foot deformities, neurological evaluation and vascular assessment (Table 12). ${ }^{55}$

\begin{tabular}{|c|c|}
\hline Evaluation & Components \\
\hline Dermatological & $\begin{array}{l}\text { - Skin status: colour, thickness, dryness, } \\
\text { cracking } \\
\text { - Sweating } \\
\text { - Infection: Check between toes for } \\
\text { fungal infection } \\
\text { - Ulceration } \\
\text { - Calluses/blistering: haemorrhage into } \\
\text { callus? }\end{array}$ \\
\hline Musculoskeletal & $\begin{array}{l}\text { - Deformity, e.g., claw toes, prominent } \\
\text { metatarsal heads, Charcot joints } \\
\text { - Muscle wasting (guttering between } \\
\text { metatarsals) }\end{array}$ \\
\hline Neurological & $\begin{array}{l}\text { 10-g monofilament }+1 \text { of the following: } \\
\text { - Vibration using } 128-\mathrm{Hz} \text { tuning fork } \\
\text { - Pinprick sensation } \\
\text { - Ankle reflexes } \\
\text { - Vibration perception threshold }\end{array}$ \\
\hline Vascular & $\begin{array}{l}\text { - Foot pulses } \\
\text { - Ankle-brachial index, if indicated }\end{array}$ \\
\hline
\end{tabular}

The patients with severe neuropathy, foot deformities or history of amputation should use specialized therapeutic footwear. ${ }^{38}$ DIAFORA is a new risk assessment model used to classify patients with diabetes and active diabetic foot ulcer by their risk of lower extremity amputation. ${ }^{56}$ (Table 13) Foot care education should be imparted to all patients with T2DM. The individuals with T2DM who smoke or have histories of prior lower-extremity complications, loss of protective sensation, structural abnormalities, or peripheral arterial disease should have ongoing preventive care and life-long surveillance. ${ }^{38}$ 
NEPAI

\begin{tabular}{|c|c|c|c|c|c|}
\hline \multicolumn{3}{|c|}{ Foot related } & \multicolumn{3}{|c|}{ DFU related } \\
\hline Variables & Definition & Points & Variables & Definition & Points \\
\hline DPN & $\begin{array}{l}\text { Inability to feel SWM at } \geq 1 \\
\text { of } 4 \text { points (hallux pulp, first, } \\
\text { third and fifth MTT heads) }\end{array}$ & 4 & Multiple DFU & Presence of $\geq 1 \mathrm{DFU}$ & 4 \\
\hline Foot deformity & $\begin{array}{l}\text { Foot alteration increasing } \\
\text { pressure in } \geq 1 \text { sites of the foot }\end{array}$ & 1 & Infection & $\begin{array}{l}\text { Purulent discharge with another } \\
\text { two local signs (warmth, } \\
\text { erythema, lymphangitis, } \\
\text { lymphadenopathy, oedema or } \\
\text { pain) }\end{array}$ & 4 \\
\hline PAD & $\begin{array}{l}\leq 1 \text { palpable pedal pulse } \\
\text { (posterior tibial and dorsalis } \\
\text { pedis arteries) }\end{array}$ & 7 & Gangrene & Presence of necrosis (dry or wet) & 10 \\
\hline $\begin{array}{l}\text { Previous DFU or } \\
\text { LEA }\end{array}$ & $\begin{array}{l}\text { History of previous DFU or } \\
\text { LEA }\end{array}$ & 3 & Bone involvement & $\begin{array}{l}\text { Bone exposure identified } \\
\text { through visual inspection, touch } \\
\text { with sterile probe and/ort bone } \\
\text { affection identified through X-ray }\end{array}$ & 7 \\
\hline \multicolumn{6}{|l|}{ Risk groups } \\
\hline Points & Risk of LEA & & & & \\
\hline$<15$ & Low & & & & \\
\hline $15-25$ & Medium & & & & \\
\hline$>25$ & High & & & & \\
\hline
\end{tabular}

DIAFORA, diabetic foot risk assessment; DFU, diabetic foot ulcer; DPN, diabetic peripheral neuropathy; LEA, lower extremity amputation; MTT, metatarsal; PAD, peripheral arterial disease; SWM, Semmes-Weinstein monofilament.

\section{Management of Specific Types of} T2DM

\section{Gestational Diabetes Mellitus}

Gestational diabetes mellitus (GDM) is defined as glucose intolerance of any severity detected during pregnancy. The indications for screening of GDM in pregnant women include history of GDM, first degree relative with diabetes, pre-pregnancy obesity, history of delivery of large weight babies, history of stillbirths or congenital anomalies, bad obstetric history, repeated or persistent urinary tract infection, glycosuria during pregnancy and age $>25$ years. ${ }^{8}$

According to the International Federation of Gynaecology and Obstetrics (FIGO), the criteria for diagnosis of GDM that is endorsed by the WHO and International Association of Diabetes in Pregnancy Study Groups (IADPSG) should be used. The FIGO guidelines for diagnosis of T2DM in pregnancy should be considered in limited resource settings. All women should be tested for hyperglycaemia during pregnancy using a onestep procedure. ${ }^{57}$ According to FIGO, the diagnosis of GDM should ideally be based on laboratory-tested venous samples. However, plasma-calibrated handheld glucometers may be used in resource poor settings. According to the IADPSG (2010) and WHO (2013) recommendations, the diagnosis of GDM is based on a single-step 75-g OGTT during pregnancy when $\geq 1$ of the following results are recorded: ${ }^{57}$

1. Fasting plasma glucose level of $92-125 \mathrm{mg} / \mathrm{dL}$

2. 1-hour post 75 -g oral glucose load level of $\geq 180 \mathrm{mg} / \mathrm{dL}$

3. 2-hour post 75-g oral glucose load level of $153-199 \mathrm{mg} / \mathrm{dL}$.

The management of GDM should be based on available healthcare infrastructure and resources. The primary tools in the management of GDM are physical activity and nutrition counselling. The patients with GDM should be counselled throughout the pregnancy and after delivery to ameliorate the future risk of T2DM and associated comorbidities..$^{57}$ A nutritionist, dietician or trained healthcare professional should provide advice 


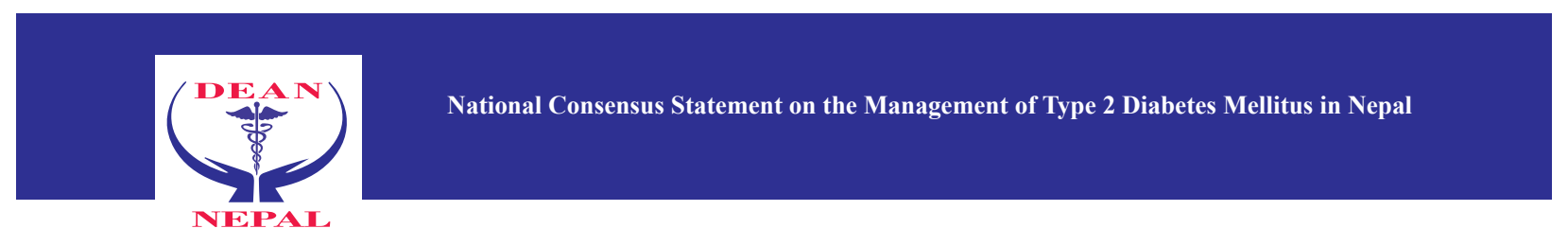

that is customized to the individual. Calorie requirement in pregnancy is estimated to be $30 \mathrm{kcal} / \mathrm{kg} /$ day. Women with pre-pregnancy $\mathrm{T} 2 \mathrm{DM}$ should receive a revised nutritional advice during pregnancy. Dietary advice should be emphasized at each clinic visit based on the pattern of weight gain. Physical exercise for a minimum of 30 minutes per day is recommended, but could be curtailed depending on the advice of a specialist. ${ }^{14}$

Insulin, metformin or glibenclamide is indicated for treatment of GDM if lifestyle measures fail to achieve glycaemic control. ${ }^{57}$ Split mixed or basal bolus insulin regimens are also indicated. The risk of hypoglycaemia should be emphasized, especially during the first trimester. After delivery, women with GDM should discontinue antidiabetic treatment and lifestyle modifications should be reinforced. Women with treated T2DM at 6-12 weeks postpartum should be screened using OGTT annually. Women who are diagnosed with prediabetes during the postnatal period should receive lifestyle interventions or metformin to prevent T2DM. ${ }^{14}$

\section{Diabetes in Older Adults}

Older adults aged $>65$ years are at increased risk for CV morbidity and mortality. Elderly T2DM patients with few chronic comorbidities and intact cognitive function and functional status should have target $\mathrm{HbA} 1 \mathrm{c}$ level of $<7.5 \%$. However, those with multiple chronic comorbidities, cognitive impairment, or functional dependence should have target HbA1c level of $<8.5 \%$. Treatment of cardiovascular risk factors should be individualized in older adults. ${ }^{58}$ The treatment for T2DM should be customized based on the geriatric syndromes such as cognitive dysfunction, functional disability, risk of falls or fractures, polypharmacy, depression as well as vision and hearing impairment. Oral hypoglycaemic agents should be prescribed with caution to elderly patients after considering their morbidity profile. ${ }^{14}$ Selection of sulphonylureas should be based on the potential of causing hypoglycaemia in elderly patients. ${ }^{59}$

\section{Diabetes in Children and Adolescents}

MODY is an umbrella term for monogenic disorders characterized by autosomal dominant inheritance of noninsulin dependent form of diabetes. MODY classically presents in adolescents or young adults aged $<25$ years. ${ }^{60}$ Sulphonylureas are effective for patients with MODY since they act on adenosine triphosphate-sensitive potassium channels. However, insulin therapy may be required at a later stage in life. ${ }^{61}$
The global prevalence of T2DM has been increasing among children and adolescents despite a pause in the obesity pandemic. Consequently, screening for T2DM is necessary for high risk groups such as children and adolescents with obesity, relatives with T2DM, and clinical features of insulin resistance (such as hypertension, dyslipidemia, polycystic ovarian syndrome, or acanthosis nigricans). ${ }^{62}$ The ADA criteria for diagnosis of T2DM remains the same for children, adolescents, and adults. The treatment for T2DM in children and adolescents is primarily focused on lifestyle management as well as pharmacotherapy at the time of diagnosis. ${ }^{63}$

\section{Relevance to Nepal}

T2DM is a major public health problem in Nepal. The Institute for Health Metrics and Evaluation (IHME) estimated that $\mathrm{T} 2 \mathrm{DM}$ was the $10^{\text {th }}$ leading cause of mortality in Nepal. The risk factors that contributed the most to death and disability from T2DM in Nepal were high fasting plasma glucose, high systolic blood pressure, dietary factors and high body mass index. ${ }^{64}$ The IDF estimated that Nepal contributed about 526,000 cases of T2DM in $2015 .{ }^{65}$

A meta-analysis of cross-sectional studies in Nepal estimated the pooled prevalence of T2DM to be $8.4 \%$. There was greater prevalence of T2DM in urban than rural areas $\left(8.1 \%\right.$ vs. $1.0 \%$, respectively). ${ }^{66}$ The NonCommunicable Diseases Risk Factors: STEPS Survey Nepal 2013 estimated the prevalence of T2DM in Nepal to be the highest among the $45-69$ years age group at $8.7 \%$ (Figure 2). ${ }^{67}$ The aforementioned study also reported high prevalence of risk factors of T2DM such as alcohol consumption, current smoking, low vegetable and fruit consumption and limited physical activity. ${ }^{68}$

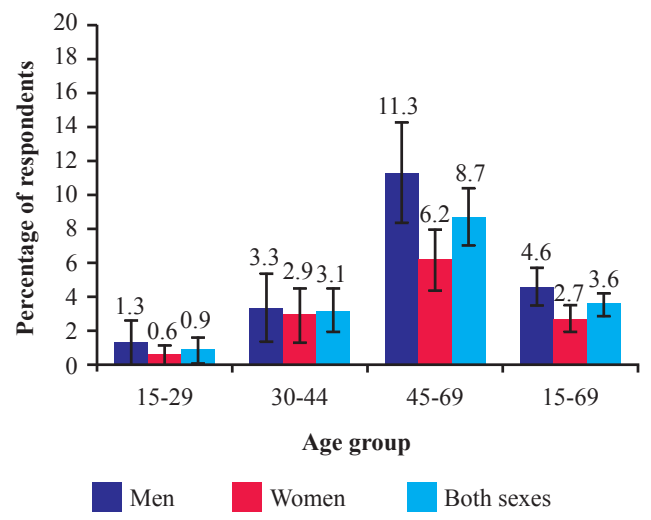

Figure 2: Prevalence of T2DM in Nepal by age groups 
The management of T2DM in Nepal is hampered by inadequate health care facilities, unaffordable treatment, limited awareness of T2DM and lack of national guidelines for healthcare providers. ${ }^{69}$ Although the international management guidelines for T2DM are well-established, the essential diagnostics and medications are found to be missing at primary healthcare facilities in Nepal. ${ }^{70}$ Lifestyle interventions as well as technology-assisted tools will be useful components of any behavioural program for preventing T2DM. ${ }^{71}$ Consequently, a multipronged approach needs to be adopted for tackling the epidemic of T2DM in Nepal.

\section{Conclusion}

T2DM is a heterogeneous endocrine disorder that is amenable to management with cost-effective strategies such as physical exercise, dietary modification and reduction of central obesity. People with T2DM who remain uncontrolled despite lifestyle changes and present with comorbidities require pharmacotherapy. The availability of generic AHAs at an affordable cost has made the internationally recognised management strategies accessible to all. Consequently, lifestyle-based preventive strategies will be important for reduction of the burden of T2DM in a resource limited country like Nepal.

\section{Recommendations}

1. $75 \mathrm{gm}$ OGTT is indicated for the diagnosis of T2DM.

2. If the FPG or 2-h PG values from OGTT or random plasma glucose are above normal, then another test is done subsequently for confirmation of the diagnosis of T2DM.

3. HbAlc level should be measured every 3 months to assess the long term glycaemic control in patients with T2DM but can be done 4-6 months if stable and finance is an issue

4. $\mathrm{SMBG}$ is useful for monitoring daily control in T2DM patients on insulin therapy, pregnancy, and brittle diabetes.

5. DSMES, MNT, physical activity, smoking cessation counseling, and psychosocial care are important components of lifestyle management for T2DM.

6. Metformin is the preferred first line oral AHA if there are no contraindications, but early combination therapy is the preferred treatment strategy when $\mathrm{HbAlc}$ is high or if they present initially with complications

7. Insulin is should be considered as first line therapy even of short term for T2DM patients with $\mathrm{HbA} 1 \mathrm{c}$ level $>10 \%$ or random blood sugar $>300 \mathrm{mg} / \mathrm{dl}$ or patient has catabolic symptoms.

8. Cardiovascular comorbidities and metabolic complications should be aggressively treated in T2DM patients.

9. T2DM patients with foot ulcers and high-risk feet should undergo more often-comprehensive foot evaluation.

10. T2DM mandates unique management strategies in children/ adolescents, pregnant women and older adults.

11. Screening for Micro and Macro vascular complications should be done annually

12. AHA failure of 3 drugs mandates the initiation of insulin therapy

13. Hypoglycaemia management and awareness should emphasized during diabetes education

14. Insulin should be encouraged during pregnancy for glycaemic control 


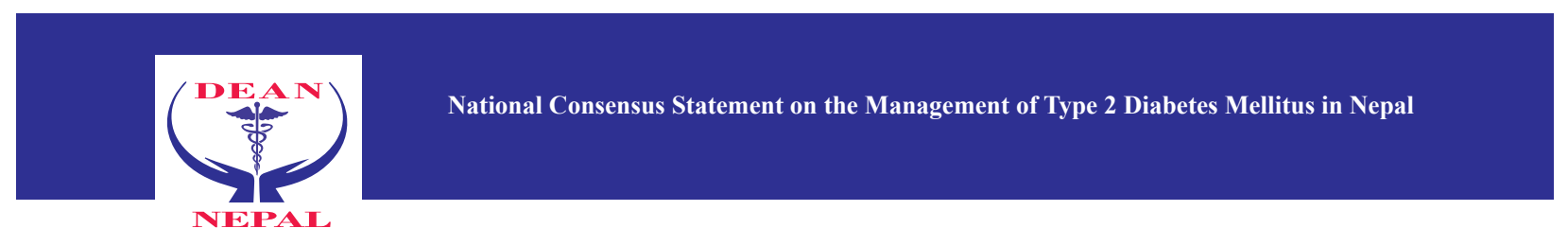

\section{References}

1. World Health Organization. Screening for Type 2 Diabetes. Report of a World Health Organization and International Diabetes Federation meeting. Geneva: Department of Noncommunicable Disease Management; 2003.

2. World Health Organization. Global report on diabetes. Geneva, Switzerland: World Health Organization; 2016.

3. International Diabetes Federation. IDF Diabetes Atlas. 7th ed. Brussels: International Diabetes Federation; 2015.

4. Zimmet PZ, Alberti KG. Epidemiology of DiabetesStatus of a Pandemic and Issues Around Metabolic Surgery. Diabetes Care. 2016;39(6):878-883.

5. Nanditha A, Ma RC, Ramachandran A, et al. Diabetes in Asia and the Pacific: Implications for the Global Epidemic. Diabetes Care. 2016;39(3):472-485.

6. American Diabetes Association. 2. Classification and Diagnosis of Diabetes: Standards of Medical Care in Diabetes - 2018. Diabetes Care. 2018;41(Supplement 1):S13-S27.

7. Harris MI, Klein R, Welborn TA, Knuiman MW. Onset of NIDDM occurs at least 4-7 yr before clinical diagnosis. Diabetes Care. 1992;15(7):815-819.

8. Indian Council of Medical Research. Guidelines for Management of Type 2 Diabetes. New Delhi: ICMR; 2005.

9. Wijeyaratne C, Somasundaram N, Illangasekara U, et al. Clinical Practice Guidelines: Management of Diabetes Mellitus. 2017.

10. Institute for Quality and Efficiency in Health Care. Glucose tolerance tests: What exactly do they involve? PubMed Health. https://www.ncbi.nlm.nih. gov/pubmedhealth/PMH0072515/.

11. Mahtab H, Khan AR, Latif ZA, Pathan F, Ahmed T. Guidelines for care of Type 2 Diabetes Mellitus in Bangladesh. Dhaka: BIRDEM Clinical Research Group; 2003.

12. Handelsman Y, Bloomgarden ZT, Grunberger G, et al. American association of clinical endocrinologists and american college of endocrinology - clinical practice guidelines for developing a diabetes mellitus comprehensive care plan - 2015. Endocr Pract. 2015;21 Suppl 1:1-87.

13. International Diabetes Federation. Global Guideline for Type 2 Diabetes. Brussels: Clinical Guidelines Task Force; 2012.

14. Somasundaram NP, Wijeyaratne CN, De Silva S, et al. Diabetes Mellitus: Glucose Control. Sri Lanka J Diab, Endo \& Metab. 2013;3:45-57.
15. American Diabetes Association. 4. Lifestyle Management: Standards of Medical Care in Diabetes - 2018. Diabetes Care. 2018;41(Supplement 1):S38-S50.

16. Sapkota S, Brien JE, Gwynn J, Flood V, Aslani P. Perceived impact of Nepalese food and food culture in diabetes. Appetite. 2017;113:376-386.

17. Mash B. Diabetes education in primary care: A practical approach using the ADDIE model. Diabet Edu. 2010;28(10):484-487.

18. Hamilton L. What Is the Plate Method? Diabetes Forecast . 2015. Ref Type: Magazine Article

19. American Diabetes Association. 8. Pharmacologic Approaches to Glycaemic Treatment: Standards of Medical Care in Diabetes - 2018. Diabetes Care. 2018;41(Supplement 1):S73-S85.

20. Berkowitz SA, Krumme AA, Avorn J, et al. Initial choice of oral glucose-lowering medication for diabetes mellitus: a patient-centered comparative effectiveness study. JAMA Intern Med. 2014;174(12):1955-1962.

21. Marin-Penalver JJ, Martin-Timon I, SevillanoCollantes C, Del Canizo-Gomez FJ. Update on the treatment of type 2 diabetes mellitus. World $J$ Diabetes. 2016;7(17):354-395.

22. Hamaty M. Insulin treatment for type 2 diabetes: when to start, which to use. Cleve Clin J Med. 2011;78(5):332-342.

23. LaSalle JR, Berria R. Insulin therapy in type 2 diabetes mellitus: a practical approach for primary care physicians and other health care professionals. J Am Osteopath Assoc. 2013;113(2):152-162.

24. Kalra S, Gupta Y. Clinical use of Insulin Degludec: Practical Experience and Pragmatic Suggestions. N Am J Med Sci. 2015;7(3):81-85.

25. Ampudia-Blasco FJ, Rossetti P, Ascaso JF. Basal plus basal-bolus approach in type 2 diabetes. Diabetes Technol Ther. 2011;13 Suppl 1:S75-S83.

26. Joshi S, Joshi P. A review of insulin and insulin regimens in type 2 diabetes. SA Fam Pract. 2009;51(2):98-102.

27. Sorli C, Heile MK. Identifying and meeting the challenges of insulin therapy in type 2 diabetes. J Multidiscip Healthc. 2014;7:267-282.

28. Garber AJ. Premixed insulin analogues for the treatment of diabetes mellitus. Drugs. 2006;66(1):3149.

29. Garber AJ, Ligthelm R, Christiansen JS, Liebl A. Premixed insulin treatment for type 2 diabetes: analogue or human? Diabetes Obes Metab. 2007;9(5):630-639. 
30. Fayfman M, Pasquel FJ, Umpierrez GE. Management of Hyperglycaemic Crises: Diabetic Ketoacidosis and Hyperglycaemic Hyperosmolar State. Med Clin North Am. 2017;101(3):587-606.

31. Stratton IM, Adler AI, Neil HA, et al. Association of glycaemia with macrovascular and microvascular complications of type 2 diabetes (UKPDS 35): prospective observational study. $B M J$. 2000;321(7258):405-412.

32. Leon BM, Maddox TM. Diabetes and cardiovascular disease: Epidemiology, biological mechanisms, treatment recommendations and future research. World J Diabetes. 2015;6(13):1246-1258.

33. Kitabchi AE, Umpierrez GE, Miles JM, Fisher JN. Hyperglycaemic crises in adult patients with diabetes. Diabetes Care. 2009;32(7):1335-1343.

34. Kitabchi AE, Umpierrez GE, Murphy MB, et al. Management of hyperglycaemic crises in patients with diabetes. Diabetes Care. 2001;24(1):131-153.

35. Umpierrez G, Korytkowski M. Diabetic emergencies - ketoacidosis, hyperglycaemic hyperosmolar state and hypoglycaemia. Nat Rev Endocrinol. 2016;12(4):222-232.

36. Dhatariya KK, Vellanki P. Treatment of Diabetic Ketoacidosis (DKA)/Hyperglycaemic Hyperosmolar State (HHS): Novel Advances in the Management of Hyperglycaemic Crises (UK Versus USA). Curr Diab Rep. 2017;17(5):33.

37. American Diabetes Association. 6. Glycaemic targets: Standards of Medical Care in Diabetes - 2018. Diabetes Care. 2018;41(Supplement 1):S55-S64.

38. American Diabetes Association. 10. Microvascular Complications and Foot Care: Standards of Medical Care in Diabetes - 2018. Diabetes Care. 2018;41(Supplement 1):S105-S118.

39. Tuttle KR, Bakris GL, Bilous RW, et al. Diabetic kidney disease: a report from an ADA Consensus Conference. Diabetes Care. 2014;37(10):2864-2883.

40. Vashist P, Singh S, Gupta N, Saxena R. Role of early screening for diabetic retinopathy in patients with diabetes mellitus: an overview. Indian J Community Med. 2011;36(4):247-252.

41. International Council of Ophthalmology. Guidelines for Diabetic Eye Care in India. January 2015. Adapted from guidelines formed by International Council of Ophthalmology. 2015.

42. Laakso M. Cardiovascular disease in type 2 diabetes: challenge for treatment and prevention. J Intern Med. 2001;249(3):225-235.
43. Juutilainen A, Lehto S, Ronnemaa $\mathrm{T}$, Pyorala $\mathrm{K}$, Laakso M. Type 2 diabetes as a "coronary heart disease equivalent": an 18-year prospective population-based study in Finnish subjects. Diabetes Care. 2005;28(12):2901-2907.

44. American Diabetes Association. 9. Cardiovascular Disease and Risk Management: Standards of Medical Care in Diabetes - 2018. Diabetes Care. 2018;41(Supplement 1):S86-S104.

45. Ferdinand $\mathrm{KC}$, Botros FT, Atisso CM, Sager PT. Cardiovascular safety for once-weekly dulaglutide in type 2 diabetes: a pre-specified meta-analysis of prospectively adjudicated cardiovascular events. Cardiovasc Diabetol. 2016;15:38.

46. Gerstein HC, Colhoun HM, Dagenais GR, et al. Design and baseline characteristics of participants in the Researching cardiovascular Events with a Weekly INcretin in Diabetes (REWIND) trial on the cardiovascular effects of dulaglutide. Diabetes Obes Metab. 2018;20(1):42-49.

47. Zhou H, Zhang X, Lu J. Progress on diabetic cerebrovascular diseases. Bosn J Basic Med Sci. 2014;14(4):185-190.

48. Ergul A, Kelly-Cobbs A, Abdalla M, Fagan SC. Cerebrovascular complications of diabetes: focus on stroke. Endocr Metab Immune Disord Drug Targets. 2012;12(2):148-158.

49. Bruno A, Liebeskind D, Hao Q, Raychev R. Diabetes mellitus, acute hyperglycaemia, and ischemic stroke. Curr Treat Options Neurol. 2010;12(6):492-503.

50. Chen R, Ovbiagele B, Feng W. Diabetes and Stroke: Epidemiology, Pathophysiology, Pharmaceuticals and Outcomes. Am J Med Sci. 2016;351(4):380-386.

51. Thiruvoipati $\mathrm{T}$, Kielhorn CE, Armstrong EJ. Peripheral artery disease in patients with diabetes: Epidemiology, mechanisms, and outcomes. World $J$ Diabetes. 2015;6(7):961-969.

52. Marso SP, Hiatt WR. Peripheral arterial disease in patients with diabetes. $J$ Am Coll Cardiol. 2006;47(5):921-929.

53. American Diabetes Association. Peripheral arterial disease in people with diabetes. Diabetes Care. 2003;26(12):3333-3341

54. Robless P, Mikhailidis DP, Stansby GP. Cilostazol for peripheral arterial disease. Cochrane Database Syst Rev. 2007;(1):CD003748. 
NEPA L

55. Boulton AJ, Armstrong DG, Albert SF, et al. Comprehensive foot examination and risk assessment: a report of the task force of the foot care interest group of the American Diabetes Association, with endorsement by the American Association of Clinical Endocrinologists. Diabetes Care. 2008;31(8):16791685.

56. Monteiro-Soares M, nis-Ribeiro M. A new diabetic foot risk assessment tool: DIAFORA. Diabetes Metab Res Rev. 2016;32(4):429-435.

57. Hod M, Kapur A, Sacks DA, et al. The International Federation of Gynecology and Obstetrics (FIGO) Initiative on Gestational Diabetes Mellitus: A Pragmatic Guide for Diagnosis, Management, and Care. International Journal of Gynecology and Obstetrics. 2015;131(S3):S173-S211.

58. American Diabetes Association. 11. Older Adults: Standards of Medical Care in Diabetes - 2018. Diabetes Care. 2018;41(Supplement 1):S119-S125.

59. Sesti G, Antonelli Inc, Bonora E, et al. Management of diabetes in older adults. Nutr Metab Cardiovasc Dis. 2018;28(3):206-218.

60. Gardner DS, Tai ES. Clinical features and treatment of maturity onset diabetes of the young (MODY). Diabetes Metab Syndr Obes. 2012;5:101-108.

61. Anik A, Catli G, Abaci A, Bober E. Maturity-onset diabetes of the young (MODY): an update. J Pediatr Endocrinol Metab. 2015;28(3-4):251-263.

62. Reinehr T. Type 2 diabetes mellitus in children and adolescents. World J Diabetes. 2013;4(6):270-281.

63. American Diabetes Association. 12. Children and Adolescents: Standards of Medical Care in Diabetes - 2018. Diabetes Care. 2018;41(Supplement 1):S126-S136.

64. Institute for Health Metrics and Evaluation. IHME. Country profiles: Nepal. 2016.

65. International Diabetes Federation. IDF SEA members: Nepal. 2017.

66. Gyawali B, Sharma R, Neupane D, Mishra SR, van TE, Kallestrup P. Prevalence of type 2 diabetes in Nepal: a systematic review and meta-analysis from 2000 to 2014. Glob Health Action. 2015;8(1):29088.

67. Nepal Health Research Council. Non Communicable Diseases Risk Factors: STEPS Survey Nepal 2013. 2014.

68. Aryal KK, Mehata S, Neupane S, et al. The Burden and Determinants of Non Communicable Diseases Risk Factors in Nepal: Findings from a Nationwide STEPS Survey. PLoS One. 2015;10(8):e0134834.
69. Gyawali B, Ferrario A, van TE, Kallestrup P. Challenges in diabetes mellitus type 2 management in Nepal: a literature review. Glob Health Action. 2016;9(1):31704.

70. Roglic G, Varghese C, Thamarangsi T. Diabetes in South-East Asia: burden, gaps, challenges and ways forward. WHO South East Asia J Public Health. 2016;5(1):1-4

71. American Diabetes Association. 5. Prevention or Delay of Type 2 Diabetes: Standards of Medical Care in Diabetes - 2018. Diabetes Care. 2018;41(Supplement 1):S51-S54. 
Notes 
NEPAL

Notes

18 